\title{
Radiographic and clinical outcomes following combined lateral lumbar interbody fusion and posterior segmental stabilization in patients with adult degenerative scoliosis
}

\author{
Zachary J. Tempel, M.D., GurPreet S. Gandhoke, M.D., \\ Christopher M. Bonfield, M.D., David O. OKonkwo, M.D., Ph.D., \\ and Adam S. Kanter, M.D. \\ Department of Neurological Surgery, University of Pittsburgh Medical Center, Pittsburgh, Pennsylvania
}

\begin{abstract}
Object. A hybrid approach of minimally invasive lateral lumbar interbody fusion (LLIF) followed by supplementary open posterior segmental instrumented fusion (PSIF) has shown promising early results in the treatment of adult degenerative scoliosis. Studies assessing the impact of this combined approach on correction of segmental and regional coronal angulation, sagittal realignment, maximum Cobb angle, restoration of lumbar lordosis, and clinical outcomes are needed. The authors report their results of this approach for correction of adult degenerative scoliosis.

Methods. Twenty-six patients underwent combined LLIF and PSIF in a staged fashion. The patient population consisted of 21 women and 5 men. Ages ranged from 40 to 77 years old. Radiographic measurements including coronal angulation, pelvic incidence, lumbar lordosis, and sagittal vertical axis were taken preoperatively and 1 year postoperatively in all patients. Concurrently, the visual analog score (VAS) for back and leg pain, the Oswestry Disability Index (ODI), and Short Form-36 (SF-36) Physical Component Summary (PCS) and Mental Component Summary (MCS) scores were used to assess clinical outcomes in 19 patients.

Results. At 1-year follow-up, all patients who underwent combined LLIF and PSIF achieved statistically significant mean improvement in regional coronal angles (from $14.9^{\circ}$ to $5.8^{\circ}, \mathrm{p}<0.01$ ) and segmental coronal angulation at all operative levels $(\mathrm{p}<0.01)$. The maximum Cobb angle was significantly reduced postoperatively (from $41.1^{\circ}$ to $\left.15.1^{\circ}, \mathrm{p}<0.05\right)$ and was maintained at follow-up $\left(12.0^{\circ}, \mathrm{p}<0.05\right)$. The mean lumbar lordosis-pelvic incidence mismatch was significantly improved postoperatively (from $15.0^{\circ}$ to $6.92^{\circ}, \mathrm{p}<0.05$ ). Although regional lumbar lordosis improved (from $43.0^{\circ}$ to $\left.48.8^{\circ}\right)$, it failed to reach statistical significance $(\mathrm{p}=0.06)$. The mean sagittal vertical axis was significantly improved postoperatively (from $59.5 \mathrm{~mm}$ to $34.2 \mathrm{~mm}, \mathrm{p}<0.01$ ). The following scores improved significantly after surgery: VAS for back pain (from 7.5 to $4.3, \mathrm{p}<0.01$ ) and leg pain (from 5.8 to $3.1, \mathrm{p}<0.01$ ), ODI (from 48 to $38, \mathrm{p}<0.01$ ), and PCS (from 27.5 to $35.0, \mathrm{p}=0.01$ ); the MCS score did not improve significantly (from 43.2 to $45.5, \mathrm{p}=0.37$ ). There were 3 major and 10 minor complications.

Conclusions. A hybrid approach of minimally invasive LLIF and open PSIF is an effective means of achieving correction of both coronal and sagittal deformity, resulting in improvement of quality of life in patients with adult degenerative scoliosis.

(http://thejns.org/doi/abs/10.3171/2014.3.FOCUS13368)
\end{abstract}

\section{Key Words • lateral lumbar fusion • posterior segmental fixation • degenerative scoliosis - lumbar lordosis}

$\mathrm{U}$ NLIKE most types of scoliosis, adult degenerative scoliosis is an acquired and progressive disease process that increases in frequency and severity with age. ${ }^{51}$ The mechanism of the condition is multifactorial and is related to progressive degenerative disc disease, compression fractures, disorders of bone quality, and osteoarthritis that creates an asymmetrical deformity of the spine in the axial, coronal, and sagittal planes. ${ }^{4,5,15,17,19,27,36,41,42,51,53,61}$

\footnotetext{
Abbreviations used in this paper: $\mathrm{ALL}=$ anterior longitudinal ligament; LL-PI = lumbar lordosis-pelvic incidence; LLIF = lateral lumbar interbody fusion; PSIF = posterior segmental instrumented fusion; ODI = Oswestry Disability Index; PEEK = polyetheretherketone; SF-36 = 36-Item Short Form Health Survey; SVA = sagittal vertical axis; VAS = visual analog score.
}

The most common symptom at presentation is a long history of progressive back pain. ${ }^{5}$ Additionally, patients may have symptoms of neurogenic claudication, radiculopathy, or significant physical limitations and emotional distress related to abnormal posture and spinal deformity., ${ }^{4,5,13}$. $14,17,27,36,41,42,53$ Surgical treatment of adult degenerative scoliosis is extremely variable and ranges from limited minimally invasive procedures to extensive and lengthy multistaged operations..$^{25,26,28,30,46,47,55,62,63}$ With an array of approaches available, we must determine which method will provide the most benefit to each individual patient.

Since its inception in the year 2006 by Pimenta ${ }^{37}$ the minimally invasive transpsoas lateral lumbar interbody fusion (LLIF) approach has gained significant favor among 
spine surgeons. It is now used to treat a multitude of conditions including degenerative disc disease, spondylolisthesis, foraminal stenosis, tumor, and trauma. ${ }^{21,31,32,37-39,58}$

Biomechanically, the interbody cage used in LLIF surgery applies an extension distraction moment to the anterior and middle columns of the lumbar spine and serves several purposes. First, it expands the interbody space, restoring lost disc space height and indirectly enlarging the neuroforamina, ultimately reducing nerve root compression. This distraction additionally induces ligamentotaxy, thus reducing dorsal annular bulging and enlarging the central canal by up to $33 \% .^{35}$

Second, by using a lordotic cage, LLIF surgery has the capability of improving lordosis. The wide cage spans the width of the vertebral body, allowing it to take advantage of the most robust area of the endplate, the cortical apophysial ring. ${ }^{40}$ Additionally, the LLIF operation is permissive in that it allows direct manipulation of the anterior and middle columns, which permits a potentially greater degree of deformity correction compared with manipulation from a posterior approach alone while minimizing blood loss and overall operative time in patients with adult degenerative scoliosis.

The LLIF has been incorporated as an adjunct treatment for adult scoliosis when combined with posterior segmental instrumented fusion (PSIF). There are an abundance of data in the literature on the ability of the LLIF surgery to significantly improve patient-reported outcome measures including visual analog score (VAS) for back and leg pain and the Oswestry Disability Index (ODI) for varying conditions. ${ }^{10,18,21,29,31-33,38,39,58}$ However, few single-center studies exist that evaluate the ability of the LLIF procedure in conjunction with PSIF to improve lumbar lordosis, correct coronal and sagittal plane deformity, and improve quality of life in patients with adult degenerative scoliosis.

We report on the 1-year clinical and radiographic results in 26 patients with adult degenerative scoliosis who underwent combined LLIF and PSIF at the University of Pittsburgh Medical Center.

\section{Methods}

This is an institutional review board-approved retrospective review of prospectively collected data at a single institution. Twenty-six consecutive patients with available preoperative and postoperative radiographs for analysis were included in this study. The patient population consisted of 21 women and 5 men. Ages ranged from 40 to 77 years old. Prior to operative management, all patients were treated conservatively with activity modification, physical therapy, chiropractic manipulations, pain medications, and/or steroid injections. Preoperatively and postoperatively, long cassette standing anteroposterior and lateral radiographs were obtained and used to measure lumbar lordosis, segmental coronal angulation, regional coronal Cobb angle, maximum Cobb angle, pelvic incidence, and sagittal vertical axis.

The general technique of LLIF has been previously described. ${ }^{37}$ Placement of a $10^{\circ}$ lordotic polyetheretherketone $(\mathrm{PEEK})$ interbody cage occurred at various levels from L1-2 to L4-5. No patient received supplementary instrumentation with a lateral plate. In this study, the spine was approached from the concavity of the scoliotic curve with the intention to approach several levels through a single incision placed at the midveterbrae of the scoliotic curve. In cases without significant coronal plane deformity, a left-sided approach was preferred because of the resilience and more ventral location of the aorta over that of the great veins. The angle of the L4-5 disc space in relation to the height of the iliac crest was another important determinant in deciding the side of the approach and limited access to that level in some cases.

All LLIF grafts were $10^{\circ}$ lordotic and packed with Intergro demineralized bone matrix (Biomet). Graft lengths ranged from 50 to $55 \mathrm{~mm}$, heights from 10 to 12 $\mathrm{mm}$, and widths from 18 to $22 \mathrm{~mm}$. To minimize subsidence, we used 22-mm-wide cages whenever possible. The length of the cage was determined by the measurement of the endplate at each level based on intraoperative fluoroscopy. The maximum distraction achieved during discectomy using the trial inserts provided an estimate of the height of the cage. Eleven patients required extension of the construct down to the pelvis, and 9 patients required placement of an interbody graft via the transforaminal approach (transforaminal lumbar interbody fusion) at L5-S1. After the LLIF, patients were placed prone on the intraoperative CT scanner bed and underwent posterior thoracolumbar-instrumented stabilization either on the same day or within 1 week. The majority of the patients underwent the total procedure under 1 session of anesthesia, as described. However, in 7 patients, the procedure was completed in 2 separate stages. A staged procedure was preferred for patients with anticipated significant blood loss and for patients who required extensive osteotomies and/or placement of an interbody graft at L5-S1. The first stage involved posterior decompression, SmithPetersen-type or pedicle subtraction osteotomies with or without screw placement, and/or placement of an interbody graft at L5-S1, as access to this disc space via the LLIF approach is anatomically unfavorable. The subsequent stage was performed within a week and consisted of LLIF surgery followed immediately by return to the prone position and opening of the posterior wound for final rod placement and fixation in the desired position. All patients who underwent a 2-stage operation required extensive Smith-Petersen-type osteotomies or a pedicle subtraction osteotomy prior to LLIF surgery to facilitate the optimal degree of distraction for the LLIF operation.

Postoperatively, patients underwent follow-up at 6 weeks, 12 weeks, 6 months, and 12 months with postoperative radiographs including dynamic and long cassette standing images to evaluate for fusion and scoliosis correction. Radiographic parameters were measured by 2 independent observers. Maximum coronal Cobb angle (Fig. 1) was measured on anteroposterior radiographs by finding the angle formed by the superior end plate of the most angulated superior vertebral body and the inferior end plate of the most angulated inferior vertebral body (the 2 end vertebrae of the major curve). Segmental coronal Cobb angles were measured using the inferior endplate of the rostral vertebral body and the superior endplate of the 

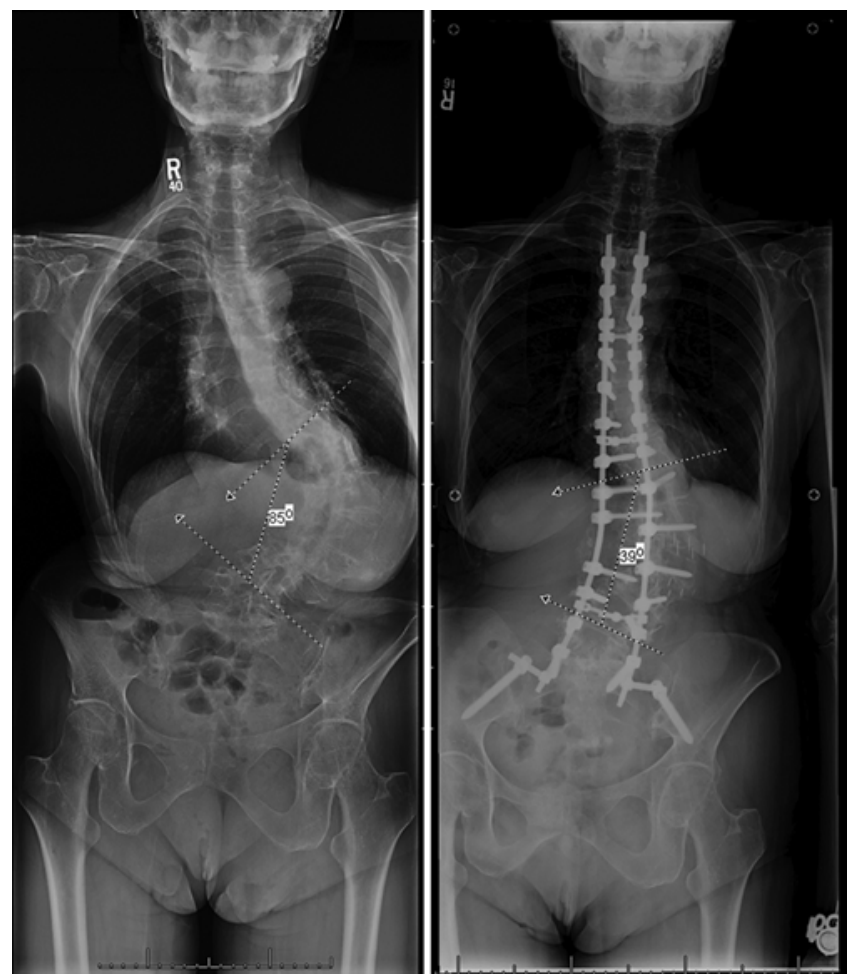

FIG. 1. Radiographs showing the maximum Cobb angle pre- and postoperatively.

caudal vertebral body (Fig. 2). The regional coronal Cobb angle was measured using the aforementioned method on anteroposterior radiographs (Fig. 3). Lordosis measurements were made on lateral radiographs using the Cobb method, measuring the angle formed between the supe-

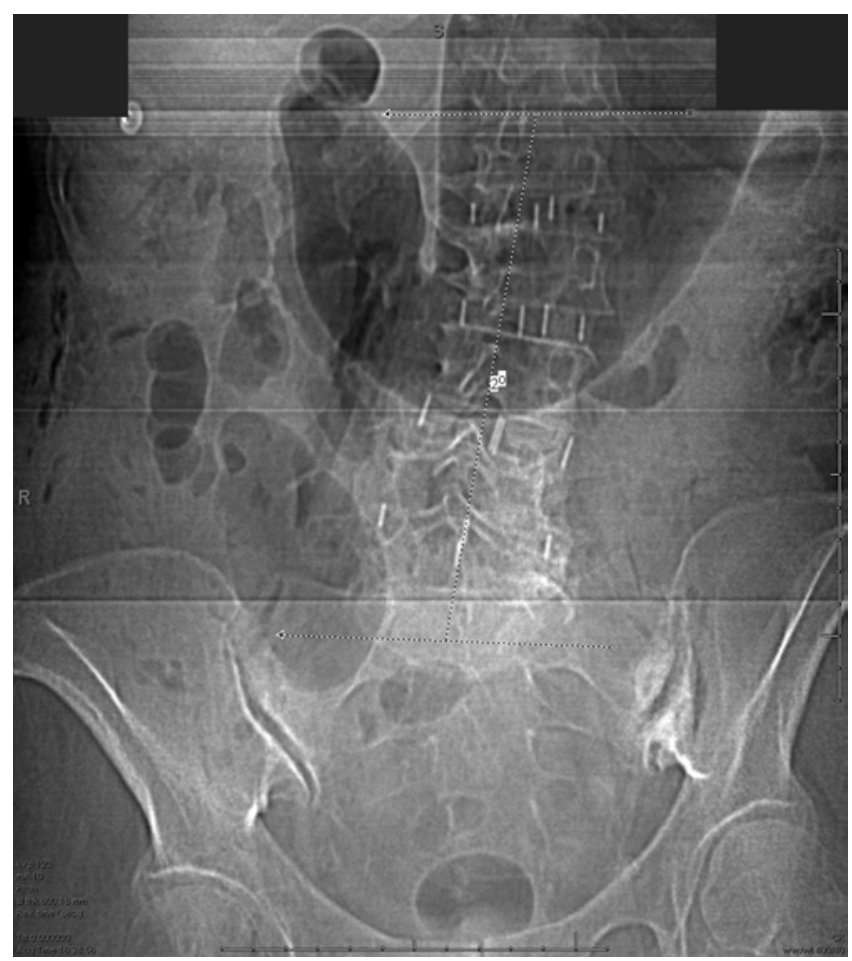

FIG. 2. Radiograph showing segmental coronal angulation.

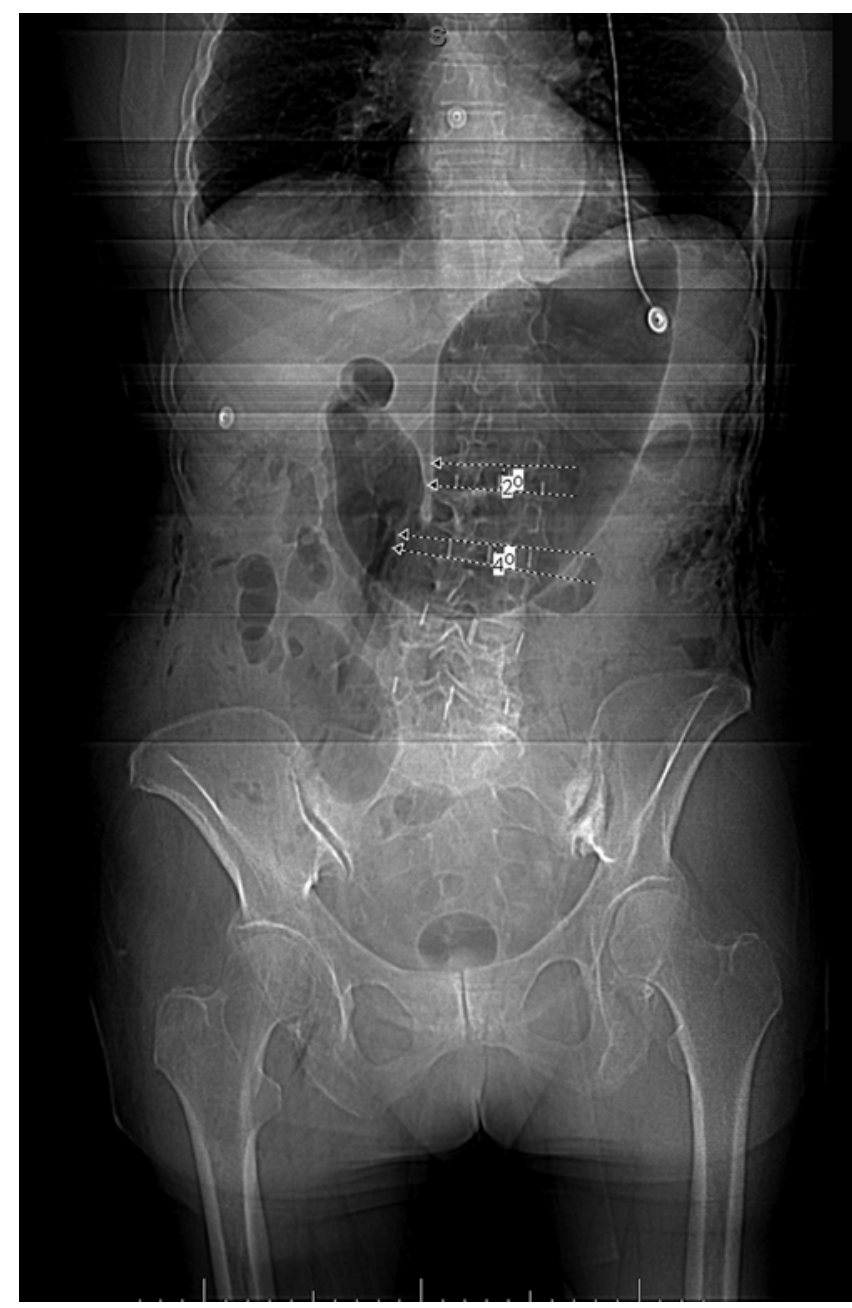

FIG. 3. Radiograph showing the regional coronal Cobb angle.

rior endplate of the L-1 vertebral body and the superior endplate of the S-1 body (Fig. 4). Pelvic incidence was calculated by determining the angle between a line oriented $90^{\circ}$ relative to the superior endplate of S-1 at the midpoint and another line from the sacral plate to midpoint of the axis of the femoral heads. Preoperative and postoperative lumbar lordosis-pelvic incidence (LL-PI) mismatch was then determined. The sagittal vertical axis (SVA) was determined both preoperatively and postoperatively by drawing a plumb line from C-7 down to S-1 and measuring its horizontal distance from the posterosuperior corner of the superior endplate of $\mathrm{S}-1$ to determine sagittal balance.

Computed tomography images and plain radiographs obtained at the 12-month postoperative mark were reviewed to assess fusion. Fusion was defined as bridging bone connecting the adjacent vertebral bodies with no angular motion or translation. These images were also reviewed for evidence of cage migration, subsidence, haloing, or failed/broken instrumentation.

Clinical data were assessed through physical examination and patient-reported questionnaires (VAS, ODI, and 36-Item Short-Form Health Survey [SF-36]) at each follow-up visit. Perioperative and postoperative complica- 


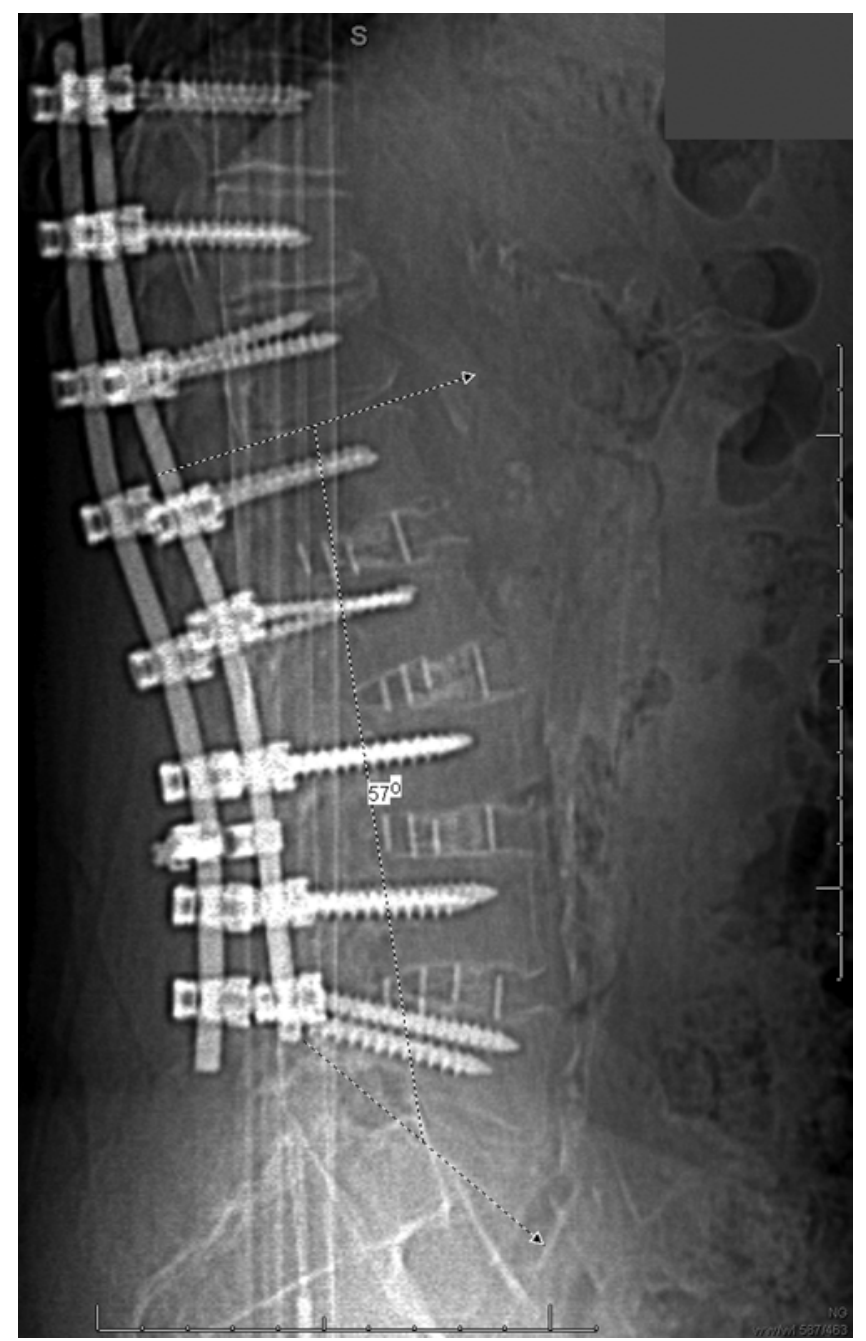

FIG. 4. Radiograph showing lumbar lordosis.

tions were also recorded. All measurements were collected and organized using an Excel spreadsheet (Microsoft). Statistical analysis was calculated using the paired t-test; a $\mathrm{p}$ value $\leq 0.05$ was considered statistically significant.

\section{Results}

Patient details are reported in Table 1. A total of 26 patients ( 5 men and 21 women) were included in the study. The mean patient age was 61 years (range 40-77 years ). All patients carried a diagnosis of adult degenerative scoliosis. Ten patients received LLIF cages across 4 lumbar levels from L-1 to L-5. Eleven patients received LLIF cages across 3 lumbar levels, either L-1 to L-4 or L-2 to L-5. Two patients received LLIF cages across 2 lumbar levels, either L-1 to L-3 or L-2 to L-4. Three patients received LLIF cages across a single lumbar level: 1 at L-2 to L-3 and 2 at L-4 to L-5. The maximum PSIF construct length spanned from T-2 to the pelvis. Eleven of the 26 patients had undergone 1 or more spinal operations at other institutions. These operations were aimed at relief of a specific symptom rather than definitive deformity correction. They included laminectomy with or
TABLE 1: Patient demographics*

\begin{tabular}{lc}
\hline \multicolumn{1}{c}{ Parameter } & Value† \\
\hline total no. of patients & 26 \\
male/female & $5: 21$ \\
mean age at time of surgery in yrs & 61 \\
total no. of levels fused (LLIF) & 80 \\
mean no. of levels fused (LLIF) & 3 \\
highest level of posterior instrumentation & T-2 \\
no. who received iliac instrumentation & 11 \\
no. who underwent a TLIF approach at L5-S1 & 9 \\
no. who underwent a staged approach ( $\geq 2$ separate & 7 \\
$\quad$ anesthesia sessions) & \\
no. who achieved successful fusion base on CT imaging & 25 \\
\hline
\end{tabular}

* TLIF = transforaminal lumbar interbody fusion.

$\dagger$ Values are number of patients unless noted otherwise.

without microdiscectomy (8 patients), single and multilevel fusions (4 patients), implantation of intrathecal opioid pumps (2 patients), synovial cyst resection (1 patient), and placement of a syringosubarachnoid shunt (1 patient). Twenty-five of 26 patients achieved solid fusion as confirmed on their CT scans at the 1-year follow-up visit. One patient demonstrated evidence of pseudarthrosis at the top of her construct 14 months after surgery and required extension of fusion to T-1.

The mean segmental coronal Cobb angle was significantly improved at all levels between L-1 and L-5 ( $p<$ 0.01 ) as depicted in Fig. 5. This correction was seen immediately postsurgery and was maintained at the 1-year follow-up. The largest preoperative mean segmental coronal Cobb angle was at L1-2 $\left(7.1^{\circ}\right)$, and the greatest relative change between preoperative and follow-up was at L4-5 (from $6.1^{\circ}$ to $0.86^{\circ}$ ).

The mean regional coronal Cobb angle was $14.9^{\circ}$ preoperatively, $7.6^{\circ}$ immediately postoperatively, and $5.8^{\circ}$ at 1 -year follow-up $(\mathrm{p}<0.01)$. The mean maximal coronal Cobb angle also improved from $41.1^{\circ}$ preoperatively to $15.1^{\circ}$ on the day of surgery and to $12.0^{\circ}$ at 1 -year followup $(\mathrm{p}<0.01)$. The mean reduction in maximum Cobb angle was $26.0^{\circ}(\mathrm{p}<0.01)$ immediately postoperatively and $29.4^{\circ}(\mathrm{p}<0.01)$ at 1-year follow-up.

The mean pre- and postoperative regional lumbar lordosis was $43.0^{\circ}$ and $48.8^{\circ}$, respectively. This trended toward, but did not reach, statistical significance $(\mathrm{p}=$ $0.06)$. The mean pre- and postoperative LL-PI mismatch (Fig. 6) was $15.0^{\circ}$ and $6.92^{\circ}$, respectively $(\mathrm{p}<0.01)$, and the mean improvement in LL-PI mismatch was $8.1^{\circ}$. The mean pre- and postoperative SVA (Fig. 7) was 59.5 and $34.2 \mathrm{~mm}$, respectively $(\mathrm{p}<0.01)$.

Clinical outcome results were available in 19 patients at the 12-month follow-up. The mean pre- and postoperative VASs for back pain were 7.5 and 4.3 , respectively ( $p<0.01)$. Improvement was also seen in the postoperative VAS for leg pain (from 5.8 preoperatively to 3.1 [p < $0.01]$ ). The mean pre- and postoperative Oswestry Disability Indices were 48 and 38 , respectively ( $\mathrm{p}<0.01$ ). The mean SF-36 Physical Component Summary score 
Lateral and posterior fusion in degenerative scoliosis

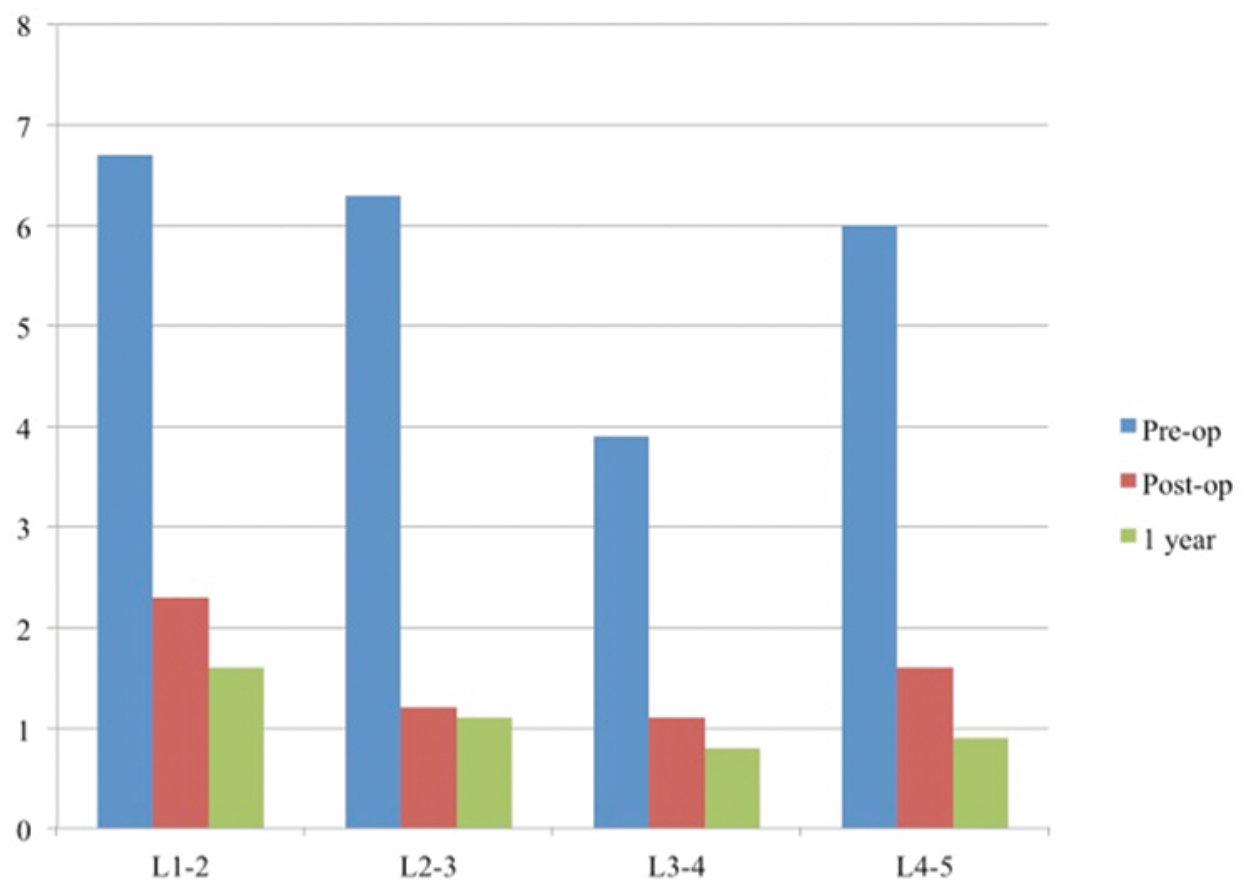

FIG. 5. Preoperative and postoperative segmental coronal angulation across each LLIF level. Units on the y axis are degrees.

improved from 27.5 to 35.0 after surgical correction $(\mathrm{p}=$ 0.01 ). However, the improvement in SF-36 Mental Component Summary score did not reach significance (from 43.2 preoperatively to $45.5, \mathrm{p}=0.37$ ).

Eleven (42.3\%) of 26 patients experienced a complication related to surgery (Table 2). Three patients (11.5\%) experienced a major complication, all related to pulmonary embolism despite receiving prophylactic doses of low-molecular-weight heparin. These patients were managed with anticoagulation in the form of a heparin drip with a transition to Coumadin for 6 months. None of these patients experienced a bleeding event as a result of anticoagulation, and all 3 of these patients recovered without adverse long-term events. Ten patients (34.6\%) experienced a minor complication. These consisted of urinary tract infection in 5 patients, unintentional durotomy in 2 patients occurring during the posterior stage of the procedure, and pleural effusion necessitating temporary pigtail drainage in 2 patients. In this series of patients, 5 (19\%) of 26 patients experienced new onset hip flexor weakness following surgery, which had resolved in all patients by the 6-week follow-up period. Three (12\%) of 26 patients experienced transient sensory dysfunction as a result of genitofemoral nerve stretch, and all patients experienced resolution of symptoms by the 6-week follow-up period.

Six patients (23\%) eventually underwent further surgical intervention following corrective surgery (Table 3). Three patients developed proximal junctional kyphosis between 14 and 24 months postoperatively and required extension of the fusion construct superiorly. One of these patients developed radiographic evidence of pseudarthrosis at the top of her construct at her 1-year follow-up appointment. One patient underwent repeat right L-4 and L-5 foraminotomies for persistent right-sided radicular symptoms approximately 16 months postoperatively. As stated previously, 1 patient had a superficial wound infection requiring a wound washout and closure with plastic surgery. One patient, who had long-standing mild leftsided S-1 radiculopathy that preceded surgery, eventually underwent intradural exploration of her left S-1 nerve root for excision of a calcified cyst due to worsening radicular symptoms.

\section{Discussion}

The LLIF procedure has the capacity to achieve spinal fusion with less morbidity than traditional open procedures. ${ }^{10,18,29,33,44,45,56}$ However, the utility of this technique in the treatment of spinal deformity, specifically with respect to adult degenerative scoliosis, has not been formally evaluated in greater detail. $2,3,10,11,18,31,34,46,47,56,60$ With release of the lateral annuli, distraction across the disc space, and placement of a large interbody graft across the entire length of the endplates, the minimally invasive LLIF approach has become a powerful tool in the armamentarium in spinal deformity correction procedures. Indeed, when combined with PSIF, it has been reported to be effective in providing varying degrees of correction of degenerative lumbar scoliotic curves with less blood loss and less morbidity than traditional open procedures. ${ }^{3,41,56}$

Anand et al. ${ }^{2}$ used the minimally invasive transpsoas approach as an adjunct to posterior stabilization in 12 patients. This study found that this approach, combined with posterior instrumented stabilization, could achieve statistically significant curve correction and improvement in quality of life measures in adult scoliosis. However, the aforementioned study incorporated minimally invasive posterior instrumentation with a maximum construct length of 8 segments. Our study examines a larger patient population utilizing the LLIF procedure in conjunction 

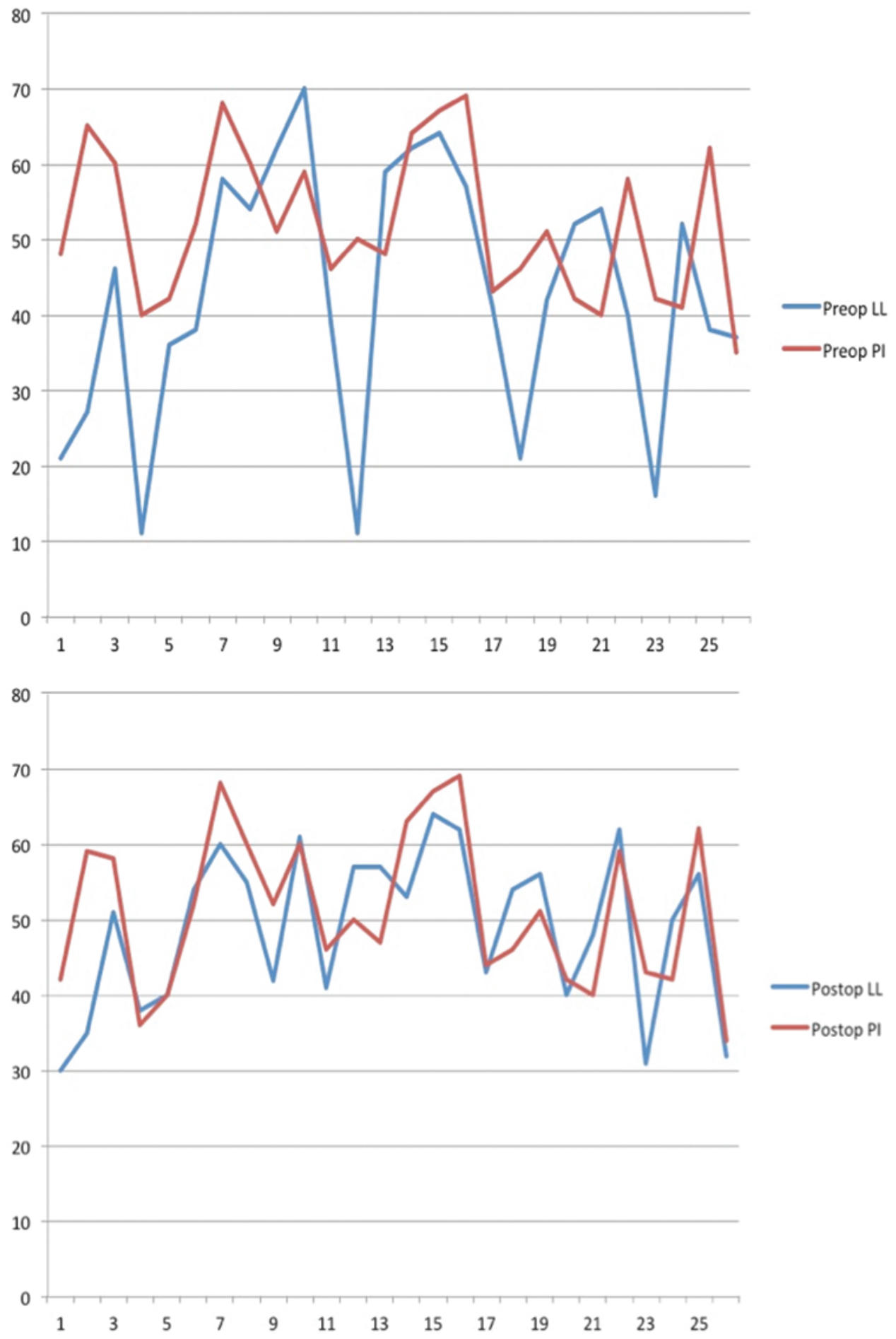

FIG. 6. Upper: Preoperative LL-PI mismatch. Lower: Postoperative LL-PI mismatch. Units on the $x$ axis are patient numbers, and units on the y axis are degrees.

with a more traditional open posterior approach. Our study similarly supports the use of the LLIF operation as a powerful adjunct to posterior stabilization. Anand et al. ${ }^{2}$ reported a mean preoperative Cobb angle of $18.93^{\circ}$ and a mean postoperative Cobb angle of $6.19^{\circ}$, while our study reports a mean preoperative Cobb angle of $41.1^{\circ}$ and a mean postoperative Cobb angle of $15.1^{\circ}$. Similarly, both studies reported statistically significant improvements in VAS scores following correction.

We found that LLIF in combination with PSIF results in statistically significant improvement in many radiographic parameters. At the 1-year mark we found a statistically significant improvement in the segmental coronal angulation at all levels in patients who underwent an LLIF 


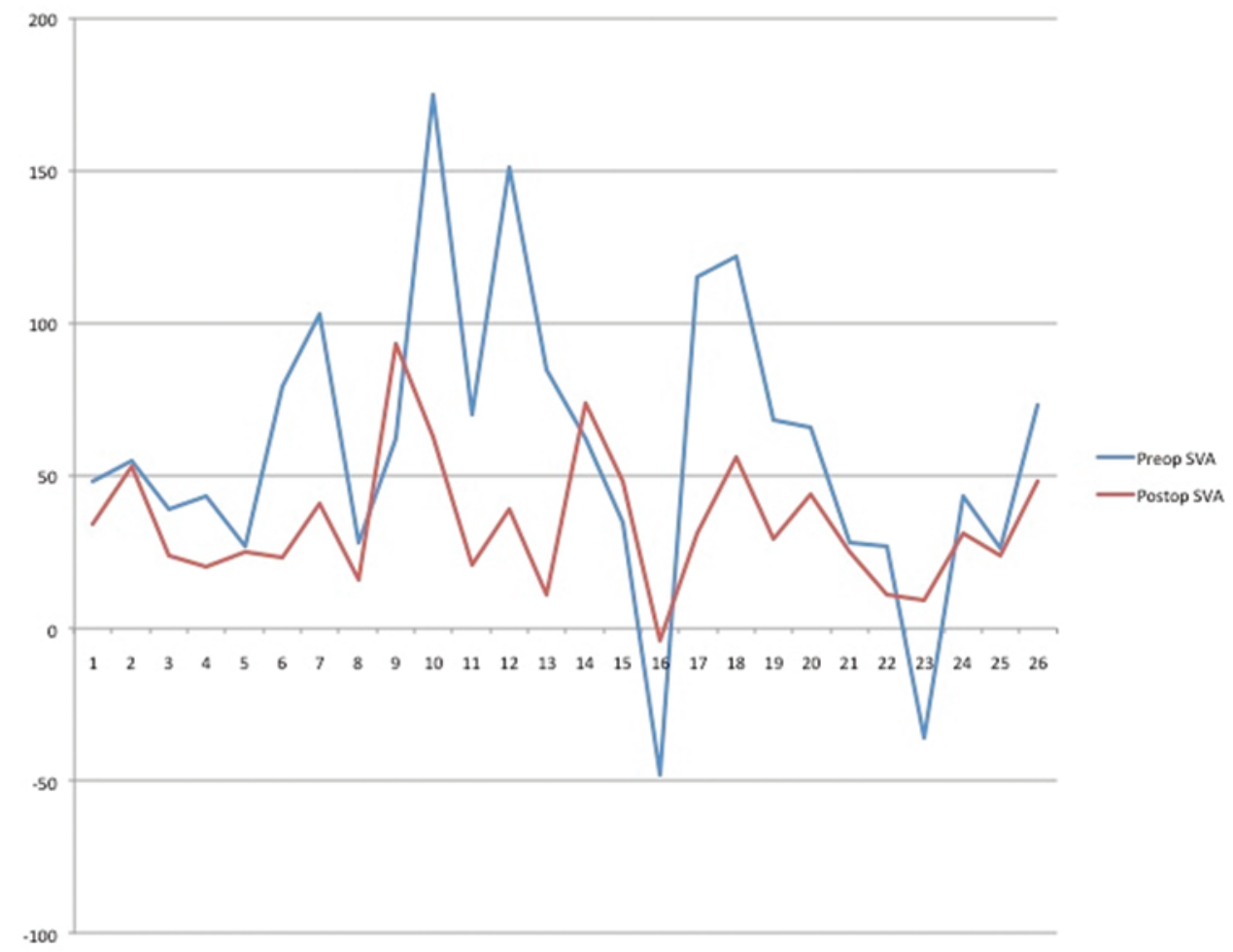

FIG. 7. Preoperative and postoperative SVA. Units on the $x$ axis are patient numbers, and units on the $y$ axis are millimeters.

with posterior stabilization. This was observed on the day of surgery and was maintained at the 1-year follow-up time point. Additionally, we found a statistically significant reduction in maximum and regional coronal Cobb angles as measured in the coronal plane postoperatively, and this was further maintained at the 1-year follow-up time point. Also, lumbar lordosis improved; however, this change failed to reach significance. Perhaps most importantly, patients who underwent combined LLIF and posterior fixation reported statistically significant improvements in a number of quality of life assessments and were physically functioning at a higher level at 1 year after surgery compared with preoperatively. This, we believe, is from the correction of the spinopelvic biomechanics as measured with the pelvic incidence and its relation to lumbar lordosis. Both patients who had previously undergone implantation of intrathecal opioid pumps had their pumps removed within 1 year after definitive corrective surgery.

Numerous studies have also investigated regional lumbar lordosis, which is directly related to global sagittal alignment. ${ }^{12,20,22,57}$ Studies have found the normal range for lumbar lordosis to be $42^{\circ}-66^{\circ} .^{24}$ Loss of lordosis is poorly tolerated in the lumbar spine, ${ }^{16,48,50}$ and its maintenance is critical to better achieve global sagittal balance. Lumbar lordosis is dependent on the sacral slope, which in turn (along with pelvic tilt) determines the pelvic incidence. Therefore, as sacral slope increases, so too do the pelvic incidence and lumbar lordosis..$^{23,43,59}$ Furthermore, the pelvic incidence and lumbar lordosis should be within $10^{\circ}$, and deviation from this parameter suggests an LL-PI mismatch. Optimal lordosis in combination with sound spinopelvic orientation is a key endpoint when evaluating sagittal deformity. Unlike lumbar lordosis, pelvic incidence is relatively constant. Therefore, in patients with sagittal plane deformity, postoperative lumbar lordosis alone does not necessarily correlate with maximum clinical and radiographic improvement. The lumbar lordosis in relation to the pelvic incidence is a more powerful radiographic parameter that predicts postoperative success.

TABLE 2: Complications and subsequent management

\begin{tabular}{lcl}
\hline \multicolumn{1}{c}{ Complication } & No. of Patients & \multicolumn{1}{c}{ Management } \\
\hline pulmonary embolism & 3 & heparin drip followed by 6 mos of oral anticoagulation \\
urinary tract infection & 5 & oral antibiotics \\
durotomy & 2 & primary repair combined w/ DuraSeal (Covidien) \\
pleural effusion & 2 & pigtail drainage \\
wound infection & 1 & intravenous antibiotics, washout, plastic surgery closure \\
transient hip flexor weakness & 5 & supportive care, physical/occupational therapy \\
transient sensory dysfunction & 3 & supportive care, physical/occupational therapy \\
\hline
\end{tabular}


TABLE 3: Further surgical intervention

\begin{tabular}{ccl}
\hline Procedure & No. of Patients & Reason \\
\hline total no. of reops & 6 & proximal junctional kyphosis \\
extension of fusion & 3 & delayed superficial wound infection \\
wound washout w/ plastic surgery closure & 1 & unilat L-4 \& L-5 radiculopathy \\
repeat hemilaminectomy + foraminotomy & 1 & unilat S-1 radiculopathy \\
excision of intradural S-1 nerve root cyst & 1 & .
\end{tabular}

Similarly, the SVA is a reliable and accurate predictor of the change in the sagittal plane deformity. ${ }^{6-8,23,48-50,54}$ The majority of patients in this study had significant coronal imbalance out of proportion to sagittal imbalance. Nevertheless, sagittal imbalance was significantly improved after surgical intervention, as evidenced by the LL-PI mismatch and SVA parameters.

In their series of 36 patients who underwent LLIF, Acosta et al. ${ }^{1}$ reported that segmental lumbar lordosis could be increased but not regional lumbar lordosis or global sagittal alignment. Of these patients, 35 had supplemental posterior instrumentation. The authors used $6^{\circ}$ lordotic cages, and immediate postoperative radiographs were obtained for comparison.

Le et al. ${ }^{22}$ recently reported that LLIF can increase segmental lordosis and disc heights significantly but not regional lordosis. Patients who underwent LLIF using a $10^{\circ}$ lordotic cage without supplemental posterior instrumentation were included. Thirty-four of the 35 patients, however, had a lateral plate placed in addition to the PEEK cage. The lateral plate does contribute to motion restriction in lateral bending and rotation with influence also on flexion and extension. ${ }^{9}$ The authors mentioned that the use of cages with more than $10^{\circ}$ lordosis and/or elective section of the anterior longitudinal ligament (ALL) could potentially provide a greater degree of lordosis.

Deukmedjian et al..$^{12}$ used $30^{\circ}$ hyperlordotic cages in 7 patients who in addition to LLIF also underwent posterior stabilization and sectioning of the ALL. At a mean follow-up of 9.1 months they found a mean increase in global lumbar lordosis of $24^{\circ}$ and an increase in segmental lordosis of $17^{\circ}$ per level of ALL released. As previously stated, although lumbar lordosis did increase postoperatively in this study, it did not reach statistical significance. However, lordosis alone is not an adequate measurement of sagittal balance. The SVA and LL-PI mismatch, which were significantly improved postoperatively in this study, are much more accurate parameters for determining the degree of sagittal imbalance. Furthermore, most patients in this series had a coronal plane deformity as the primary problem, which was the primary target of surgical intervention.

The findings in our study correlate with those in other studies regarding the effectiveness of a combined lateral and posterior approach in correction of adult degenerative scoliosis. As stated previously, the LLIF renders the vertebrae susceptible to biomechanical manipulation through release of anatomical tension bands and likely permits greater curve correction than stand-alone posterior fixation. Furthermore, the low morbidity and mini- mally invasive nature of the LLIF procedure may reduce overall blood loss and complications from a more difficult posterior-only operation, which would require more extensive osteotomies and involve significant manipulation of the spine posteriorly without access to the anterior or middle columns. It would be useful in the future to do further studies to delineate the degree of permissive correction achieved with LLIF when used in conjunction with posterior fixation, performed in both a minimally invasive and open fashion.

Hip flexor weakness, resulting from stretching of the iliopsoas muscle during the lateral placement of the interbody graft, is commonly seen after LLIF surgery. There are multiple studies in press that have reported on the incidence of hip flexor weakness following LLIF surgery, ranging from $15 \%$ to $25 \% .^{1-4}$ In this series, the incidence of transient hip flexor weakness is 19\%, which is consistent with the reported risk of transient hip flexor weakness following LLIF surgery. Sharma et al. ${ }^{52}$ reported a $25 \%$ incidence of postoperative anterior thigh numbness as a result genitofemoral nerve trauma after LLIF. In our series, the incidence of transient thigh numbness is $12 \%$, which is consistent with the reported risk of transient thigh numbness after LLIF surgery. It should be noted that although the major complication rate (for example, death or paralysis) for lateral transpsoas surgery is low, such complications do occur. At our institution, we report a prior death in 1 patient after a bowel perforation during a stand-alone LLIF operation. This patient did not meet inclusion criteria for this study.

\section{Conclusions}

A hybrid approach to patients with spinal deformity related to adult degenerative scoliosis that combines the minimally invasive LLIF operation with open PSIF allows for significant radiographic correction and improvement in quality of life with acceptable complication rates. Other studies are in process to evaluate the influence of stand-alone LLIF versus LLIF with posterior segmental stabilization on global spinal parameters including sagittal balance, coronal balance, and pelvic incidence.

\section{Disclosure}

Dr. Okonkwo reports that he receives royalties from Lanx. Dr. Kanter reports receiving non-study-related clinical or research support from NuVasive and royalties from Lanx for a minimally invasive surgery retractor (not used for the patients in this study).

Author contributions to the study and manuscript preparation include the following. Conception and design: Gandhoke, Okonkwo, 
Kanter. Acquisition of data: Tempel, Gandhoke. Analysis and interpretation of data: all authors. Drafting the article: Tempel, Gandhoke, Okonkwo. Critically revising the article: all authors. Reviewed submitted version of manuscript: all authors. Approved the final version of the manuscript on behalf of all authors: Tempel. Statistical analysis: Gandhoke. Administrative/technical/material support: Bonfield. Study supervision: Okonkwo, Kanter.

\section{References}

1. Acosta FL, Liu J, Slimack N, Moller D, Fessler R, Koski T: Changes in coronal and sagittal plane alignment following minimally invasive direct lateral interbody fusion for the treatment of degenerative lumbar disease in adults: a radiographic study. Clinical article. J Neurosurg Spine 15:92-96, 2011

2. Anand N, Baron EM, Thaiyananthan G, Khalsa K, Goldstein TB: Minimally invasive multilevel percutaneous correction and fusion for adult lumbar degenerative scoliosis: a technique and feasibility study. J Spinal Disord Tech 21:459-467, 2008

3. Anand N, Rosemann R, Khalsa B, Baron EM: Mid-term to long-term clinical and functional outcomes of minimally invasive correction and fusion for adults with scoliosis. Neurosurg Focus 28(3):E6, 2010

4. Benner B, Ehni G: Degenerative lumbar scoliosis. Spine (Phila Pa 1976) 4:548-552, 1979

5. Birknes JK, White AP, Albert TJ, Shaffrey CI, Harrop JS: Adult degenerative scoliosis: a review. Neurosurgery 63 (3 Suppl):94-103, 2008

6. Blondel B, Pomero V, Moal B, Lafage V, Jouve JL, Tropiano $\mathrm{P}$, et al: Sagittal spine posture assessment: feasibility of a protocol based on intersegmental moments. Orthop Traumatol Surg Res 98:109-113, 2012

7. Blondel B, Schwab F, Ungar B, Smith J, Bridwell K, Glassman $\mathrm{S}$, et al: Impact of magnitude and percentage of global sagittal plane correction on health-related quality of life at 2-years follow-up. Neurosurgery 71:341-348, 2012

8. Boulay C, Tardieu C, Hecquet J, Benaim C, Mouilleseaux B, Marty C, et al: Sagittal alignment of spine and pelvis regulated by pelvic incidence: standard values and prediction of lordosis. Eur Spine J 15:415-422, 2006

9. Cappuccino A, Cornwall GB, Turner AW, Fogel GR, Duong $\mathrm{HT}, \mathrm{Kim} \mathrm{KD}$, et al: Biomechanical analysis and review of lateral lumbar fusion constructs. Spine (Phila Pa 1976) 35 (26 Suppl):S361-S367, 2010

10. Caputo AM, Michael KW, Chapman TM Jr, Massey GM, Howes CR, Isaacs RE, et al: Clinical outcomes of extreme lateral interbody fusion in the treatment of adult degenerative scoliosis. ScientificWorldJournal 2012:680643, 2012

11. Dakwar E, Cardona RF, Smith DA, Uribe JS: Early outcomes and safety of the minimally invasive, lateral retroperitoneal transpsoas approach for adult degenerative scoliosis. Neurosurg Focus 28(3):E8, 2010

12. Deukmedjian AR, Le TV, Baaj AA, Dakwar E, Smith DA, Uribe JS: Anterior longitudinal ligament release using the minimally invasive lateral retroperitoneal transpsoas approach: a cadaveric feasibility study and report of 4 clinical cases. Laboratory investigation. J Neurosurg Spine 17:530539, 2012

13. Epstein BS, Epstein JA, Jones MD: Symptomatic lumbar scoliosis with degenerative changes in the elderly. Tex Med 74: 56-64, 1978

14. Epstein JA, Epstein BS, Jones MD: Symptomatic lumbar scoliosis with degenerative changes in the elderly. Spine (Phila Pa 1976) 4:542-547, 1979

15. Fu KM, Rhagavan P, Shaffrey CI, Chernavvsky DR, Smith JS: Prevalence, severity, and impact of foraminal and canal stenosis among adults with degenerative scoliosis. Neurosurgery 69:1181-1187, 2011

16. Glassman SD, Bridwell K, Dimar JR, Horton W, Berven S,
Schwab F: The impact of positive sagittal balance in adult spinal deformity. Spine (Phila Pa 1976) 30:2024-2029, 2005

17. Grubb SA, Lipscomb HJ, Coonrad RW: Degenerative adult onset scoliosis. Spine (Phila Pa 1976) 13:241-245, 1988

18. Isaacs RE, Hyde J, Goodrich JA, Rodgers WB, Phillips FM: A prospective, nonrandomized, multicenter evaluation of extreme lateral interbody fusion for the treatment of adult degenerative scoliosis: perioperative outcomes and complications. Spine (Phila Pa 1976) 35 (26 Suppl):S322-S330, 2010

19. Jimbo S, Kobayashi T, Aono K, Atsuta Y, Matsuno T: Epidemiology of degenerative lumbar scoliosis: a community-based cohort study. Spine (Phila Pa 1976) 37:1763-1770, 2012

20. Johnson RD, Valore A, Villaminar A, Comisso M, Balsano M: Pelvic parameters of sagittal balance in extreme lateral interbody fusion for degenerative lumbar disc disease. J Clin Neurosci 20:576-581, 2013

21. Karikari IO, Nimjee SM, Hardin CA, Hughes BD, Hodges TR, Mehta AI, et al: Extreme lateral interbody fusion approach for isolated thoracic and thoracolumbar spine diseases: initial clinical experience and early outcomes. J Spinal Disord Tech 24:368-375, 2011

22. Le TV, Vivas AC, Dakwar E, Baaj AA, Uribe JS: The effect of the retroperitoneal transpsoas minimally invasive lateral interbody fusion on segmental and regional lumbar lordosis. ScientificWorldJournal 2012:516706, 2012

23. Legaye J, Duval-Beaupère G, Hecquet J, Marty C: Pelvic incidence: a fundamental pelvic parameter for three-dimensional regulation of spinal sagittal curves. Eur Spine J 7:99-103, 1998

24. Lin RM, Jou IM, Yu CY: Lumbar lordosis: normal adults. J Formos Med Assoc 91:329-333, 1992

25. Liu HY, Zhou DG, Wang HM, Yi B, Wang B, Jin ZH, et al: [Surgical treatment of degenerative scoliosis.] Zhonghua Wai Ke Za Zhi 41:33-36, 2003 (Chinese)

26. Liu HY, Zhou DG, Wang HM, Yi B, Wang B, Jin ZH, et al: [Surgical treatment of degenerative scoliosis.] Zhonghua Yi Xue Za Zhi 83:1066-1069, 2003 (Chinese)

27. Liu W, Chen XS, Jia LS, Song DW: The clinical features and surgical treatment of degenerative lumbar scoliosis: a review of 112 patients. Orthop Surg 1:176-183, 2009

28. Liu Z, Zhao QH, Wu XZ, Song R, Yuan G, Tian JW: [Short fusion and long fusion for degenerative lumbar scoliosis with lumbar stenosis.] Zhonghua Yi Xue Za Zhi 92:1751-1755, 2012 (Chinese)

29. Malham GM, Ellis NJ, Parker RM, Seex KA: Clinical outcome and fusion rates after the first 30 extreme lateral interbody fusions. ScientificWorldJournal 2012:246989, 2012

30. Mao ZG, Wu QX, Zhu JM, Li CD, Zhu TY: [Surgical treatment for degenerative lumbar scoliosis associated with spinal stenosis.] Zhongguo Gu Shang 21:860-862, 2008 (Chinese)

31. Marchi L, Abdala N, Oliveira L, Amaral R, Coutinho E, Pimenta L: Stand-alone lateral interbody fusion for the treatment of low-grade degenerative spondylolisthesis. ScientificWorldJournal 2012:456346, 2012

32. Marchi L, Oliveira L, Amaral R, Castro C, Coutinho T, Coutinho E, et al: Lateral interbody fusion for treatment of discogenic low back pain: minimally invasive surgical techniques. Adv Orthop 2012:282068, 2012

33. Marchi L, Oliveira L, Coutinho E, Pimenta L: Results and complications after 2-level axial lumbar interbody fusion with a minimum 2-year follow-up. Clinical article. J Neurosurg Spine 17:187-192, 2012

34. Mundis GM, Akbarnia BA, Phillips FM: Adult deformity correction through minimally invasive lateral approach techniques. Spine (Phila Pa 1976) 35 (26 Suppl):S312-S321, 2010

35. Oliveira L, Marchi L, Coutinho E, Pimenta L: A radiographic assessment of the ability of the extreme lateral interbody fusion procedure to indirectly decompress the neural elements. Spine (Phila Pa 1976) 35 (26 Suppl):S331-S337, 2010 
36. Oskouian RJ Jr, Shaffrey CI: Degenerative lumbar scoliosis. Neurosurg Clin N Am 17:299-315, vii, 2006

37. Ozgur BM, Aryan HE, Pimenta L, Taylor WR: Extreme Lateral Interbody Fusion (XLIF): a novel surgical technique for anterior lumbar interbody fusion. Spine J 6:435-443, 2006

38. Pimenta L, Oliveira L, Schaffa T, Coutinho E, Marchi L: Lumbar total disc replacement from an extreme lateral approach: clinical experience with a minimum of 2 years' follow-up. Clinical article. J Neurosurg Spine 14:38-45, 2011

39. Pimenta L, Smith W, Taylor W, Uribe J: Lateral access surgery for the thoracolumbar spine. ScientificWorldJournal 2013:241705, 2013

40. Pimenta L, Turner AW, Dooley ZA, Parikh RD, Peterson MD: Biomechanics of lateral interbody spacers: going wider for going stiffer. ScientificWorldJournal 2012:381814, 2012

41. Ploumis A, Transfledt EE, Denis F: Degenerative lumbar scoliosis associated with spinal stenosis. Spine J 7:428-436, 2007

42. Pritchett JW, Bortel DT: Degenerative symptomatic lumbar scoliosis. Spine (Phila Pa 1976) 18:700-703, 1993

43. Rajnics P, Templier A, Skalli W, Lavaste F, Illés T: The association of sagittal spinal and pelvic parameters in asymptomatic persons and patients with isthmic spondylolisthesis. J Spinal Disord Tech 15:24-30, 2002

44. Rodgers WB, Cox CS, Gerber EJ: Early complications of extreme lateral interbody fusion in the obese. J Spinal Disord Tech 23:393-397, 2010

45. Rodgers WB, Gerber EJ, Patterson J: Intraoperative and early postoperative complications in extreme lateral interbody fusion: an analysis of 600 cases. Spine (Phila Pa 1976) 36:2632,2011

46. Scheufler KM, Cyron D, Dohmen H, Eckardt A: Less invasive surgical correction of adult degenerative scoliosis. Part I: technique and radiographic results. Neurosurgery 67:696710,2010

47. Scheufler KM, Cyron D, Dohmen H, Eckardt A: Less invasive surgical correction of adult degenerative scoliosis. Part II: Complications and clinical outcome. Neurosurgery 67:16091621,2010

48. Schwab F, Lafage V, Boyce R, Skalli W, Farcy JP: Gravity line analysis in adult volunteers: age-related correlation with spinal parameters, pelvic parameters, and foot position. Spine (Phila Pa 1976) 31:E959-E967, 2006

49. Schwab FJ, Blondel B, Bess S, Hostin R, Shaffrey CI, Smith JS, et al: Radiographical spinopelvic parameters and disability in the setting of adult spinal deformity: a prospective multicenter analysis. Spine (Phila Pa 1976) 38:E803-E812, 2013

50. Schwab FJ, Smith VA, Biserni M, Gamez L, Farcy JP, Pagala M: Adult scoliosis: a quantitative radiographic and clinical analysis. Spine (Phila Pa 1976) 27:387-392, 2002

51. Seo JY, Ha KY, Hwang TH, Kim KW, Kim YH: Risk of progression of degenerative lumbar scoliosis. Clinical article. J Neurosurg Spine 15:558-566, 2011

52. Sharma AK, Kepler CK, Girardi FP, Cammisa FP, Huang RC, Sama AA: Lateral lumbar interbody fusion: clinical and ra- diographic outcomes at 1 year. A preliminary report. J Spinal Disord Tech 24:242-250, 2011

53. Silva FE, Lenke LG: Adult degenerative scoliosis: evaluation and management. Neurosurg Focus 28(3):E1, 2010

54. Smith JS, Shaffrey CI, Glassman SD, Carreon LY, Schwab FJ, Lafage V, et al: Clinical and radiographic parameters that distinguish between the best and worst outcomes of scoliosis surgery for adults. Eur Spine J 22:402-410, 2013

55. Sun ZM, Zhao D, Deng SC, Zhao HY: [Surgical options and result analyses in adult degenerative lumbar scoliosis.] Zhonghua Yi Xue Za Zhi 89:1166-1170, 2009 (Chinese)

56. Tormenti MJ, Maserati MB, Bonfield CM, Okonkwo DO, Kanter AS: Complications and radiographic correction in adult scoliosis following combined transpsoas extreme lateral interbody fusion and posterior pedicle screw instrumentation. Neurosurg Focus 28(3):E7, 2010

57. Uribe JS, Smith DA, Dakwar E, Baaj AA, Mundis GM, Turner AW, et al: Lordosis restoration after anterior longitudinal ligament release and placement of lateral hyperlordotic interbody cages during the minimally invasive lateral transpsoas approach: a radiographic study in cadavers. Laboratory investigation. J Neurosurg Spine 17:476-485, 2012

58. Uribe JS, Smith WD, Pimenta L, Härtl R, Dakwar E, Modhia UM, et al: Minimally invasive lateral approach for symptomatic thoracic disc herniation: initial multicenter clinical experience. Clinical article. J Neurosurg Spine 16:264-279, 2012

59. Vaz G, Roussouly P, Berthonnaud E, Dimnet J: Sagittal morphology and equilibrium of pelvis and spine. Eur Spine J 11: 80-87, 2002

60. Wang MY, Mummaneni PV: Minimally invasive surgery for thoracolumbar spinal deformity: initial clinical experience with clinical and radiographic outcomes. Neurosurg Focus 28(3): E9, 2010

61. Wu HL, Ding WY, Shen Y, Zhang YZ, Guo JK, Sun YP, et al: Prevalence of vertebral endplate modic changes in degenerative lumbar scoliosis and its associated factors analysis. Spine (Phila Pa 1976) 37:1958-1964, 2012

62. Wu JH, Xu WX, Lai SJ, Wang J, Lu D: [Surgical treatment of degenerative lumbar scoliosis with spinal stenosis.] Zhongguo Gu Shang 25:459-462, 2012 (Chinese)

63. Xie J, Zhang Y, Wang Y: [Posterior approach to treatment of spinal stenosis associated with degenerative lumbar scoliosis.] Zhongguo Xiu Fu Chong Jian Wai Ke Za Zhi 22:711-714, 2008 (Chinese)

Manuscript submitted August 16, 2013.

Accepted March 19, 2014.

Please include this information when citing this paper: DOI: 10.3171/2014.3.FOCUS13368.

Address correspondence to: Zachary J. Tempel, M.D., University of Pittsburgh Medical Center, Neurological Surgery, UPMC Presbyterian, 200 Lothrop St., Ste. B400, Pittsburgh, PA 15213. email: tempelzj@upmc.edu. 